\title{
English-Medium Instruction in the Education Faculty of Málaga University: Students' profiles
}

\section{Barrios, Elvira $^{\text {a }}$ and López-Gutiérrez, Aurora ${ }^{\text {a }}$}

Facultad de Ciencias de la Educación, Campus de Teatinos, Universidad de Málaga, Málaga, 29071, Spain

\begin{abstract}
This paper seeks to attain a better knowledge of the students that have joined the first partially-taught-in-English degree course in one of the six groups of the Bachelor's Degree in Primary Education in the University of Málaga. The aim is to comprehend their different profiles so that professors can cater for their needs. To achieve this objective, as part of an innovation project led by a multidisciplinary team, different questionnaires were designed, the first of them to get information about their personal data and English training. It was taken by first year students, for two consecutive years $(2014,2015)$.

The results of this questionnaire revealed that, as no specific requirements were asked, and only English level indications were given, we have to work with an heterogeneous group of people, which results in a multi-level proficiency, very demanding group, to deal with. However, comparing the results from one year to the next, we noticed that there has been an improvement in almost every parameter we were interested in assessing, and the participants of the developing innovation project are committed to evaluate their needs and provide the necessary support that teachers and students deserve.
\end{abstract}

Keywords:. Tertiary Education; English medium instruction; Student profiles; English training; proficiency level; innovation project. 


\section{Introduction}

English medium instruction (EMI) in tertiary education is a significant growth area, with over half of the world's international students being taught in English, and universities offering an increasing range of courses in this language (Graddol, 2006). The ultimate challenge is to be fluent in English, acquire and convey knowledge through this language, and therefore, be able to communicate in the lingua franca the western world has adopted as a means of communication, so greater efforts to integrate content and language can be seen in post Bologna Europe (Doiz, Lasagabaster, \& Sierra, 2013).

In Málaga University (UMA) this is a recent phenomenon, and English Medium instruction has been implemented in one of the groups of future Primary Education teachers, the present year being the second of their four year degree. After the first years' experience, regarding the outcomes of a questionnaire about the student's background and expectations, this challenge has definitively been taken seriously, and the multidisciplinary professionals involved have created a PIE ("Programa de Innovación Educativa" or Innovation Project in Education) to follow the developing curriculum and make changes as necessary; to complete their instruction, to create and share materials, and ultimately, to improve the quality of the degree course.

This first task aimed to ascertain the students' background and their previous educational profiles, so the teaching staff could adapt their classes to the level of the students in the vehicle language, making the necessary changes. With this aim in mind, we produced a questionnaire which has been filled in by first year students in two consecutive years, and it has provided us a vast amount of useful information which will be very relevant for our purpose.

\section{Questionnaires results : Students' profiles}

\subsection{Personal data}

The former academic year (2014-15) group was formed by 68 students, though the questionnaires were completed by 61 of them. Most of them were women (77\%), the sample age ranged from 17 to 30 years old, the majority being 18 (59\%). Eight of them were 17 when they filled out the questionnaire (13.1\%), and ten were already $19(16.4 \%)$, the seven left were between 20 and 30 years old.

More than half of them studied in State primary and secondary schools (56\%), while 39\% came from private centres, and the $5 \%$ left were from private centres that receive State 
funds. Only one had studied in an English curriculum school. Virtually every one of them (97\%) came from "Bachillerato" (equivalent of the A-levels in Great Britain or $12^{\text {th }}$ grade High School in the U.S.A) and passed the university access exams. The other $3 \%$ came to the University as mature students.

The present academic year (2015-16) gives us similar data. The group is formed by 67 students, and 62 completed the questionnaire, (of which $79 \%$ were women), plus five Erasmus students that will study only during the first term. At the time of the questionnaire, 32 were 18 years old $(51.6 \%)$, while fourteen were 17 years old $(22.6 \%)$. The rest were in a 19 to 45 year-old range. There were five 19-year-old students $(8.1 \%)$, four 20-year-olds $(6.5 \%)$, six between 21 and 30, and just one of them older than 45 .

This time there are even more students that come from State schools (75\%), only 5\% come from private schools, and the rest $(17.7 \%)$ come from private centres with State funding. Two of them had studied for a while in English curriculum schools, and another two have already finished another university degree. In this sample 91,9\% had accessed from "Bachillerato" and passed the university access exams.

The university access exam, together with the "Bachillerato" mark, averaged out, gives the overall mark which determines the possibility of studying certain degrees. Last year, students were admitted into this group with an average of 7.874 , while this year that number has raised to 8.999 , or more, in order to get a place there.

Table 1. University access overall mark for the partially-taught-in English Bachelor's Degree in the UMA: Bachillerato and University access exam. Comparison between consecutive years

\begin{tabular}{ll}
\hline Year & Average \\
\hline 2014 & 7,874 \\
2015 & 8,999 \\
\hline
\end{tabular}

Considering that last year this course was not known by the student community, and wasn't well advertised, this year there has been an improvement in the promotion of this course (though in my point of view, it is still insufficient) and by word of mouth, more students requested entrance than the previous year. The increase in the mark required for acceptance onto this course shows a growing interest for this type of instruction and therefore, in time, could reflect in higher social esteem for teachers. 


\subsection{Formal English training and level of proficiency}

One of our main interests was to know the students' previous instruction in the target language, as they were not subjected to any specific entry requirements in that area. Not only was it important to learn about their level of English through the exams they had taken (Cambridge, Trinity, Official Language School, etc.), but also their experiences throughout the educational system, (Type of school and secondary School: bilingual or not, foreign curriculum, etc.) and those gained in a non formal environment (international exchanges, student mobility, etc..). We even took into account their personal assessment about their proficiency level in the English Language. The questionnaires show the following results in these matters:

In 2014 only $4.9 \%$ of the students had studied in bilingual primary schools and $14.8 \%$ in bilingual secondary schools. A year later those percentages had raised to $12.9 \%$ of students in bilingual primary schools and $19.4 \%$ in secondary schools. This data displays the ongoing rise in bilingual schools in our community, due to the implementation of bilingual programmes in the Andalusian school system since 2005, as well as the good level of acceptance from these students for this type of instruction. Although for many years, the country's national level of English has remained one of the lowest in the European Union (EUROSTAT, 2010), and therefore a very low percentage of higher students could study and work in this language, (Dafouz, E., Camacho, M. \& Urquía, E., 2014); as a result of a decade of CLIL implementation measures in Spain in compulsory education settings, there may soon be 'a new generation of students (and teachers) in tertiary education, who will consider learning through a foreign language a common practice' (Dafouz and Núñez 2009, p. 110).

The previous year, $11.5 \%$ had studied at one of the Official Language schools $(6.6 \%$ English courses) and the present year, $19.4 \%$ of them had studied or is studying there now (12.9\% English courses). In comparison, last year $42.6 \%$ of them had passed at least one of the Cambridge or Trinity exams, and this course more than half has, (51.6\%), mostly at intermediate level (B1 or B2).

When asked for their personal opinion about their English level within the Common European Framework of Reference for Languages (CEFR) though, in the first year most of them situated themselves as follows: in B1 level, 71.7\%; the next highest group 14.8\%, thought that they were at B2 level; $9.8 \%$ considered themselves as having an A2 level, and only $3.3 \%$ felt were at the highest levels (C1-C2). In this second year, the figures go up in the upper-intermediate levels: a total of $51.6 \%$ feel they are at B1 level and $38.7 \%$ at B2 
(90.3\% in total), while the others, beginners (A2) and advanced (C1-C2) are very similar to the previous years' figures. Nonetheless, it is very common that some students overestimate their proficiency levels, or even situate themselves in very different ones according to their competence in the four skills (oral, reading, listening and writing).

Table 2. Appreciation of level of English. Comparison between consecutive years

\begin{tabular}{llll}
\hline Year & A2 & B1-B2 & C1-C2 \\
\hline 2014 & $9.8 \%$ & $86.5 \%$ & $3.3 \%$ \\
2015 & $8.1 \%$ & $90.3 \%$ & $1.6 \%$ \\
\hline
\end{tabular}

Source: Student Profiles questionnaire (2016)

Regarding their personal experiences abroad, again we noticed an increase in the percentage of students that have participated in international exchanges, comparing this year with the year before, varying from $39.3 \%$ in 2014 to $48.4 \%$ in 2015 . As before, the students mobility in secondary education between countries had raised as well, from only $9.8 \%$ in 2014 , to $16.1 \%$ in 2015 .

Finally we enquired about their expectations at joining this group, and they all coincided in admitting the increasing importance of mastering English in our society, allowing them better job opportunities in the future by improving their linguistic competence and their curriculum; similar expectations other studies have stated before (Wilkinson, 2013, p.16). In both years most of them expected to have at least $50 \%$ of the contents taught in English, which wasn't the case in the first year, as only one of the teachers involved fulfilled this requirement. Students also demanded lectures with a high oral English competence, and different kinds of linguistic support (a language advisor, conversation classes and different elective courses to choose from, depending on their needs), have been the most solicited, as well as the students requesting proper feedback about their language skills.

\section{Conclusions}

The results obtained from these questionnaires have drawn the following conclusions:

This group of students is mostly formed by women, with an average age of eighteen years old, who predominantly come from 'Bachillerato' studies within the State School System, had a previous English instruction to an intermediate level, and aimed to join the EMI class 
in the Education Faculty of Málaga University as a way to continue their training, improve their competence in the English language, and enhance their employability.

While their self-assessment on their linguistic competence is normally higher than the factual data they can provide, they are still very far from being a homogeneous group in that sense, some of them exhibiting fear at not being able to follow the classes, in contrast with others that consider the general level too low for their own expectations, making a very difficult task for their teachers to manage their instruction.

As previous studies on CLIL have stated (See Aguilar and Rodríguez, 2012; Dalton Puffer, 2008; Lyster, 2007) when at the end of the first year, students were asked about their perception of language skills improvements, although no significantly changes were appreciated, the two skills that they considered to have improved the most, were listening and speaking, as opposed to reading and writing.

To meet with their demands, and improve the quality of the Degree, a collaborative interdisciplinary innovation project has been designed and later approved by the University of Málaga Vice-rectorate for Academic Organisation and Teaching Staff with the subsequent challenges:

- Continue improving the lecturer's instruction in CLIL methodologies and English proficiency, offering training courses, together with the FGUMA (Fundación General de la Universidad de Málaga ).

- Facilitate the exchange of experiences and coordination among the staff involved in the EMI and external collaborators, through monthly meetings, online contacts and forums.

- Invite different professionals to organize seminars and workshops about bilingual Education and implementation of the Bilingual School System in our community.

- $\quad$ Request that fourth year students from the Degree of English Studies conduct their practice time with this group as language advisors; correcting pronunciation and writing essays, giving students and teachers feedback, etc. This idea has been carried out with success in Cordoba University as part of their plurilingualism plan for the last few years (Fontanet, I., 2015). This point has actually already been approved and four language advisors, or mentors, have been assigned to this group next term.

- Create online resources to provide information about the partly-taught-in English Bachelor's Degree in Primary Education group, to enhance the possibility of 
encouraging more international students to participate, as part of the Erasmus programme.

- Encourage the submission of papers by the innovation project participants, to publicise the results.

- $\quad$ Further research to identify the effect of the second language on content learning. As Wilkinson \& Zeggers stated: 'If only negative effects can be observed, then the longer-term outlook for content learning through a foreign language may be at risk. Simply demonstrating positive effects on language learning may be insufficient... What is required is research into the impact that foreign-languagemedium instruction has on the ability of students to communicate content knowledge in their mother tongue' (Wilkinson, R., \& Zegers, V., 2008, p. 7).

\section{References}

Aguilar, M. \& Rodríguez, R. (2012). "Lecturer and student perceptions on CLIL at a Spanish university". International Journal of Bilingual Education and Bilingualism, 15(2), 183-197. DOI:10.1080/13670050.2011. 615906

Dafouz, E., Camacho, M. \& Urquía, E. (2014) 'Surely they can't do as well': a comparison of business students' academic performance in English-medium and Spanish-as-firstlanguage-medium programmes, Language and Education, 28:3, 223-236, DOI: 10.1080/09500782.2013.808671

Dafouz, E., \& B. Núñez. 2009. "CLIL in Tertiary Education: Devising a New Learning Landscape." In CLIL Across Educational Levels, edited by E. Dafouz, and M.C. Guerrini, pp. 101-112. Madrid: Richmond.

Dalton-Puffer, C. 2008, "Outcomes and processes in CLIL: current research from Europe",in Delanoy, W. and Volkman, L. (Eds)., Future Perspectives for English Language Teaching, Heidelberg, Carl Winter.

Doiz, A., Lasagabaster, D \& Sierra, J. M. (2013). Future Challenges for English-Medium Instruction at the tertiary level. In A. Doiz, D. Lasagabaster \& J. M. Sierra. (eds). English-Medium Instruction at Universities, pp. 213-221. Bristol, Multilingual matters.

EUROSTAT 2010 Population and social conditions. Statistics in Focus, 49/2010. http://epp.eurostat.ec.europa.eu/cache/ITY_OFFPUB/KS-SF-10-049/EN/KS-SF-10049-EN.PDF

Fontanet-Gómez, I. (2015). The implementation of a multilingual language policy in a time of economic restrictions. In Wilkinson, R. \& Walsh, M. L. (Eds.) Integrating Content and Language in Higher Education. From Theory to Practice, pp. 75-89. Frankfurt, Peter Lang Edition

Graddol, D. (2006) English Next. Plymouth: British Council.

Lyster, R. (2007). Learning and teaching languages through content: A counterbalanced approach. Amsterdam/Philadelphia, John Benjamins. 
Wilkinson, R. (2013). English-medium instruction at a Dutch university: Challenges and pitfalls. In A. Doiz, D. Lasagabaster, \& J.M. Sierra (Eds.). English-medium instruction at universities: Global challenges (pp. 3-24). Bristol: Multilingual matters.

Wilkinson, R., \& Zegers, V. (2008). Introduction. In R. Wilkinson \& V. Zegers (Eds.). Realizing content and language integration in higher education, pp. 1-9. Maastricht: Maastricht University. 